\title{
Heteropagus twins with hepatobiliary and gastrointestinal connectedness and complex cardiac malformation in autosite
}

Aaron Teel, Benjamin Kwan, Mousumi Bhaduri

\section{ABSTRACT}

Introduction: Heteropagus twins are a set of conjoined twins with one being grossly abnormal, the 'parasite', and the other being relatively normal, the 'autosite'.

Case Report: A pair of heteropagus twins were initially identified on prenatal ultrasound and subsequently confirmed using prenatal MRI at 25 weeks gestational age. Prenatal imaging identified supernumerary limbs, accessory small bowel loops in the parasitic twin, a hypoplastic left heart in the right hemithorax of the autosite, and a shared liver and bowel between the two. Delivery occurred at $38+5$ weeks gestation via $\mathrm{C}$-section with an APGAR score of 9/9 for the autosite at both 1 and 5 minutes. MRI confirmed an interconnected autosite-parasite liver that was herniating into the left hemithorax as well as continuous autosite-parasite bowel loops. The patient underwent surgical management including resection of the parasitic twin and repair of the congenital heart defect and is now thriving.

Discussion: Heteropagus twins include a spectrum of clinical entities from nonconjoined twins to intact conjoined twins. The predominant theory regarding etiology is an incomplete cleavage of a monozygotic embryo at approximately 2 weeks gestation. Following differentiation, ischemia-induced atrophy leads to the embryonic death of the parasite and hemodynamic changes in the autosite to support parasite tissues. The use of antenatal and postnatal imaging is crucial in establishing the diagnosis, management plan, and longterm prognosis secondary to the congenital cardiac malformations and degree of interconnectedness.

Conclusion: This is the first reported case of heteropagus twins with co-existing hepatobiliary and gastrointestinal continuity.

\section{INTRODUCTION}

Heteropagus or parasitic twins consist of a conjoined grossly abnormal parasite twin attached externally to a relatively normal autosite twin. ${ }^{1}$ This condition is reportedly extremely rare, commonly quoted to occur at an incidence of 1-2 per million live births or approximately $10 \%$ of conjoined twins. ${ }^{2-5}$ This is based on old US data and there does not appear to be current comprehensive tracking of this condition. ${ }^{2}$ Consequently, little is known regarding factors that contribute to this entity. ${ }^{3}$

The most frequent anatomical variant, occurring in roughly $53 \%$ of cases, involves connection between the thorax and umbilicus and is referred to as omphalopagus. ${ }^{3}$ Less frequent variants include fusion at the hip (ischiopagus), spine (rachipagus), and head (craniopagus). ${ }^{3}$ Continuity of visceral structures between heteropagus twins is rare. ${ }^{3}$ The parasitic twin usually only consists of a group of externally attached supernumerary limbs. ${ }^{1}$ The parasite is typically acephalic and lacks cardiac tissue or limb movement. Congenital cardiac malformations are common in the autosite. ${ }^{3}$

We present a case of omphalopagus heteropagus twins with hepatobiliary and gastrointestinal continuity and a complex cardiac malformation in the autosite.

\section{CASE REPORT}

The patient was referred to the fetal development clinic from the community with suspicion of fetus-in-fetu, a parasitic twin found within the body of a host co-twin. ${ }^{6}$ Prenatal ultrasound at 25 weeks 1 day gestational age revealed a single intrauterine gestation, likely female, with three additional limbs arising from the anterior thorax/abdominal wall region (Fig. 1). Two of the limbs appeared to be protruding from the sternum with one arising inferiorly. There also appeared to be an intrathoracic soft tissue mass, which was displacing the mediastinum and heart to the right. The autosite was also noted to have a hypoplastic left heart.

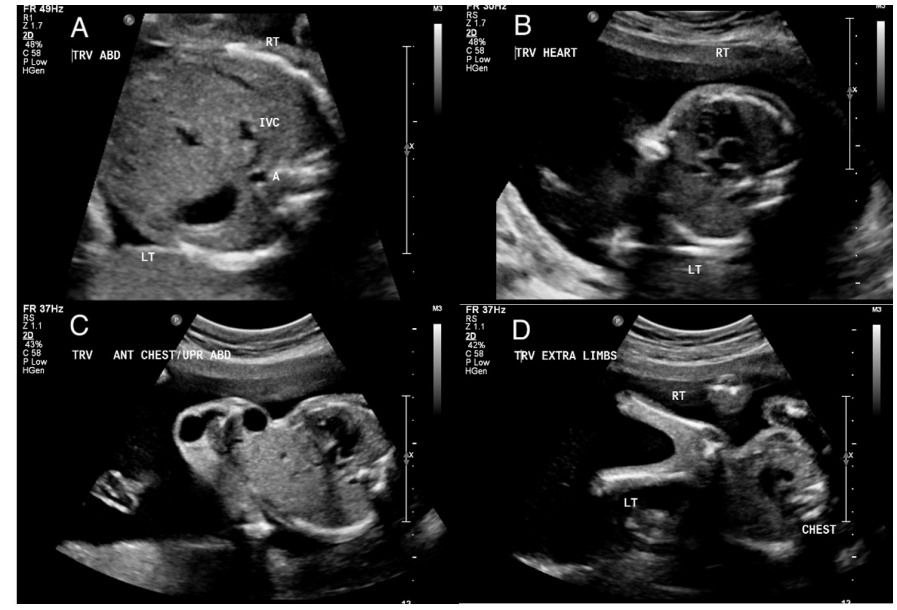

Figure 1. Axial antenatal ultrasound of autosite shows stomach on the left side (A) and dextrocardia with a hypoplastic left heart (B). A soft tissue protrusion with same echotexture as fetal liver and cystic regions representing bowel is shown arising from the anterior chest/upper abdomen (C). At the level of the autosite sternum, a bone is shown coursing anteriorly dividing into two limbs (D).

A fetal MRI was performed to better assess these findings (Fig. 2). The MRI confirmed the presence of three external supernumerary limbs. Also attached was what appeared to be a lower abdomen containing tubular cystic spaces, thought to be small bowel, and an external liver. The external liver was contiguous with the intra-thoraco-abdominal liver in the fetus, with the heart in the right hemithorax. 

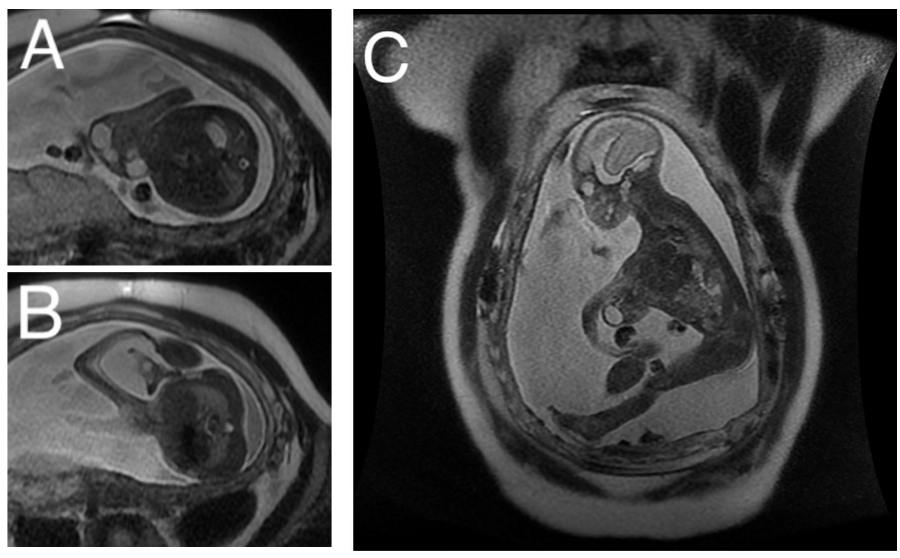

Figure 2. Axial antenatal MRI of autosite shows a soft tissue protrusion containing tubular cystic spaces and an external liver contiguous with autosite liver (A). Axial and coronal antenatal MRI at level of autosite sternum showing a bone coursing anteriorly dividing into two limbs ( $B$ and $C$ ).

The case was presented at multidisciplinary rounds consisting of a team of fetal-maternal health physicians, medical geneticists, neonatologists, pediatric surgeons, and diagnostic radiologists. Based on the prenatal ultrasound and MRI findings, including the presence of supernumerary limbs, the diagnosis of heteropagus twinning was made instead of fetus-in-fetu. The team, in discussion with family, elected for expectant management.

Term delivery occurred at $38+5$ weeks gestation via C-section. APGAR score of the autosite was $9 / 9$ at 1 and 5 minutes. The infant was admitted to the NICU. Echocardiography revealed dextroversion, hypoplastic left heart with aortic atresia, retrograde ductus blood flow into the ascending aorta, patent ductus arteriosus with bidirectional shunt, two small ventricular septal defects, a nonrestrictive foramen ovale, and small pulmonary artery branches.

Postnatal X-ray and MRI were performed (Figs. 3 and 4). Postnatal MRI of the thorax and abdomen demonstrated herniation of the left liver lobe of the autosite into the left hemithorax via a large ventral diaphragmatic defect. The liver of the autosite appeared to be conjoint to the liver of the parasite. There also appeared to be shared bowel loops between the twins with herniation similar to the liver.

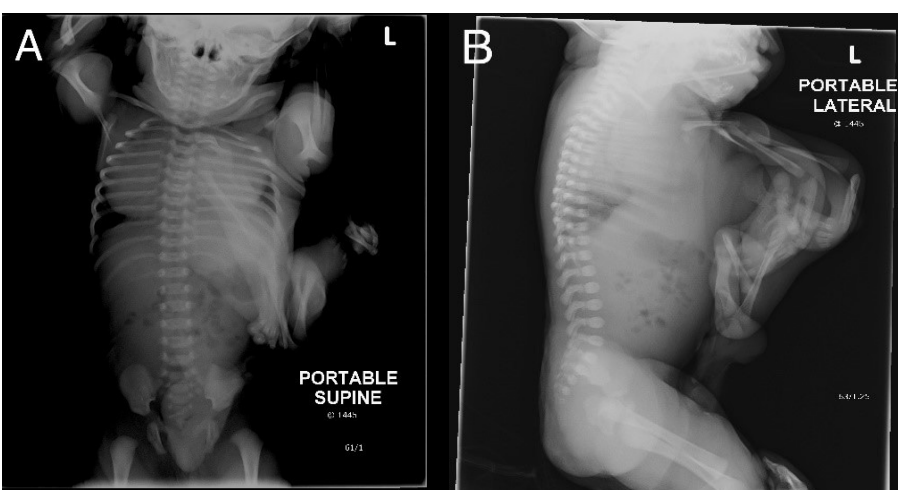

Figure 3. Postnatal AP (A) and lateral (B) X-rays showing supernumerary limbs protruding from thorax with superimposed normal upper limbs of autosite.

Clinically the parasite appeared to have a patent anus. The image findings of bowel communication were confirmed when the parasite produced stool-like material in response to the initiation of enteral feeding. The heteropagus twins were transferred to a quaternary referral center for potential surgical management including resection of the parasitic twin and repair of the congenital heart defect. Subsequent surgical management included stenting for patent ductus arteriosus, primary repair of Morgagni hernia, relocation of liver into abdomen, bowel resection, limb amputations, and autologous skin implants. At last follow-up, at 2 years of age, the patient was thriving but was expected to need continued management of the complex cardiac malformation.

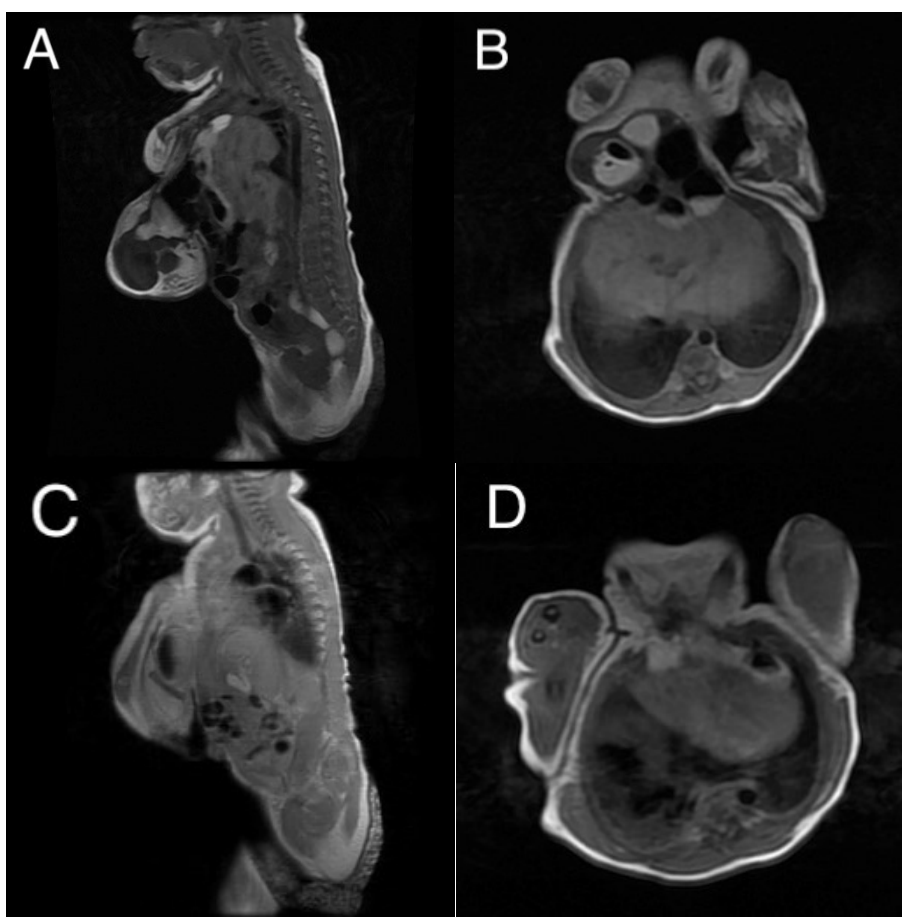

Figure 4. Postnatal sagittal (A) and axial (B) MRI showing herniation of left liver lobe into left hemithorax through a large ventral diaphragmatic defect in autosite as well as shared bowel loops between autosite and parasite. Postnatal sagittal (C) and axial (D) MRI showing the parasite pelvis at the level of the autosite manubrium.

\section{DISCUSSION}

The most comprehensive review to date on heteropagus twins describes the condition as, "a spectrum of clinical entities ranging from nonconjoined twins to intact conjoined twins."” There are two main competing theories regarding the embryologic development of heteropagus twins: incomplete fission of the blastocyst and fusion of distinct inner cell masses. ${ }^{3}$ The predominant theory is that a process of incomplete fission occurs at approximately 2 weeks with DNA analysis showing monozygotic origin between twins supporting this notion. ${ }^{3,7,8}$ Following differentiation, the parasitic twin experiences ischemia-induced atrophy due to either insufficient parasite cardiac function or vascular steal from the autosite, leading to its embryonic death. ${ }^{9}$ Some parasitic tissues remain and become dependent on collaterals from the autosite, as evidenced by autosite-derived vascular pedicles identified in the parasite during surgical intervention. ${ }^{3}$ This leaves an acardiac parasite and an autosite susceptible to cardiac malformations thought to be due to the hemodynamic changes associated with providing perfusion to parasite tissues. ${ }^{10}$ 
Prenatal imaging is important in distinguishing heteropagus twinning from more severe congenital malformations as the former may be managed surgically. ${ }^{3}$ Identification of a treatable condition may avoid unnecessary termination of the pregnancy. In the presented case, the condition was originally thought to be a fetus-in-fetu. Fetus-in-fetu typically presents as an intra-abdominal mass within a single fetus and requires different post-delivery surgical planning and follow up., ${ }^{3,6}$ Prenatal imaging allowed the clinicians to make the correct diagnosis of heteropagus twinning by identification of the distinct features of external limbs and lack of enclosure of the parasite within a sac. As there are many forms of twinning occurring along a spectrum, review of the salient imaging features of each category is necessary to distinguish heteropagus twinning from other forms. Presentation at multidisciplinary rounds with fetal-maternal health physicians and medical geneticists was thought to be helpful at arriving at the correct diagnosis in this case.

Imaging through the use of MRI, ultrasound, and CT is also useful prior to surgical separation in order to distinguish parasitic and autositic tissues and for determining the anatomy of conjoined organs. ${ }^{3,11}$ Outcomes regarding survival have been shown to be more favourable in heteropagus twins compared to symmetric conjoined twins, due to a lesser degree of connectedness. ${ }^{3}$ The leading cause of death in the autosite is cardiorespiratory failure secondary to congenital cardiac malformation. ${ }^{3}$

There have only been four previous reports of hepatobiliary connectedness in heteropagus twins with one case having separate autosite and parasite livers and three cases having fused livers. ${ }^{3,8,9,12,13}$ In addition, there have been thirteen previous cases with parasitic bowel present with only one case demonstrating communication between autosite and parasite bowel., ${ }^{3,714}$ However, none of these cases had co-existing hepatobiliary and gastrointestinal continuity, which makes this the first reported case of its kind.

Congenital cardiac malformation occurs frequently in the autositic twin, affecting $23 \%$ of all autosites and $39 \%$ of omphalopagus autosites. ${ }^{3}$ The mechanism by which these malformations occur has been postulated to be due to hemodynamic alterations to support the parasitic twin. ${ }^{10}$ The prevalence of cardiac abnormalities renders echocardiography mandatory in all autosites and particularly with omphalopagus heteropagus twins. ${ }^{4}$

Many of the structural cardiac abnormalities noted in the present case, including aortic atresia, hypoplasia of the left ventricle, patent ductus arteriosus, and ventricular septal defects have been previously documented., ${ }^{5,15,16}$ However, we were not able to locate any previous reports of dextroversion.

\section{CONCLUSION}

We report the first known case of heteropagus twins with coexisting hepatobiliary and gastrointestinal interconnectedness. The diagnosis of heteropagus twinning was made prenatally through the use of ultrasound and MRI. Following birth, MRI was used to evaluate anatomy between autosite and parasite, for guiding management decisions, and ultimately to guide the surgical approach.

\section{REFERENCES}

1. Spencer R. Parasitic conjoined twins: external, internal (fetuses in fetu and teratomas), and detached (acardiacs). Clin Anat. 2001 Nov;14(6):428-44. https://doi.org/10.1002/ca.1079

2. Edmonds LD, Layde PM. Conjoined twins in the united states, 1970-1977. Teratology. 1982 Jun;25(3):301-8. https://doi. org/10.1002/tera.1420250306

3. Sharma G, Mobin SS, Lypka M, et al. Heteropagus (parasitic) twins: a review. J Pediatr Surg. 2010 Dec;45(12):2454-63. https://doi.org/10.1016/j.jpedsurg.2010.07.002

4. Abubakar AM, Ahidjo A, Chinda JY, et al. The epigastric heteropagus conjoined twins. J Pediatr Surg. 2011 Feb;46(2):417-20. https://doi.org/10.1016/j. jpedsurg.2010.09.045

5. Ozkan-Ulu H, Yilmaz Y, Sari FN, et al. An unusual case of heteropagus: autosite with a complex cardiac malformation. Pediatr Neonatol. 2011 Dec;52(6):358-60. https://doi. org/10.1016/j.pedneo.2011.08.011

6. Sitharama SA, Jindal B, Vuriti MK, et al. Fetus in fetu: case report and brief review of literature on embryologic origin, clinical presentation, imaging and differential diagnosis. Pol J Radiol. 2017 Jan 30;82:46-49. https://doi.org/10.12659/ PJR.899956

7. Kanamori Y, Tomonaga T, Sugiyama M, et al. Bizarre presentation of epigastric heteropagus: report of a case. Surg Today. 2006;36(10):914-8. https://doi.org/10.1007/s00595-006$\underline{3275-9}$

8. Xie JT, Zhou L, Yang ZL, et al. Epigastric heteropagus conjoined twins: two case studies and associated DNA analysis. Clinics (Sao Paulo). 2012;67(5):527-9. https://doi.org/10.6061/ clinics $/ 2012(05) 22$

9. De Ugarte DA, Boechat MI, Shaw WW, et al. Parasitic omphalopagus complicated by omphalocele and congenital heart disease. J Pediatr Surg. 2002 Sep;37(9):1357-8. https:// doi.org/10.1053/jpsu.2002.35011

10. Logroño R, Garcia-Lithgow C, Harris C, et al. Heteropagus conjoined twins due to fusion of two embryos: report and review. Am J Med Genet. 1997 Dec 19;73(3):239-43. https:// doi.org/10.1002/(SICI)1096-8628(19971219)73:3<239::AIDAJMG1>3.0.CO;2-N

11. Baskaran D, Aleem MA, Ravi R. Parasitic twin with gastroschisis is one of the rarest variant of conjoined twins: a case report. Indian J Surg. 2015 Apr; 77(Suppl 1):90-1. https:// doi.org/10.1007/s12262-014-1165-8

12. George AT, Varkey S, Kalam A, et al. Left over bowels: an unique complication in a surviving twin. Postgrad Med J. 2004 Dec;80(950):736-7. https://doi.org/10.1136/pgmj.2004.023499

13. Mabogunje OA, Lawrie JH. The heteropagus conjoined twins of NDU Sule, Nigeria. Clin Pediatr (Phila). 1978 Nov;17(11):8613. https://doi.org/10.1177/000992287801701111

14. Das S, Ghosh D, Biswas S, et al. Heteropagus twins-a tale of two cases. Indian J Surg. 2011 Jun;73(3):217-20. https://doi.org/ $10.1007 / \mathrm{s} 12262-010-0228-8$ 
15. O’Neill JA Jr, Holcomb GW 3rd, Schnaufer L, et al. Surgical experience with thirteen conjoined twins. Ann Surg. 1988 Sep;208(3):299-312. https://doi.org/10.1016/S00223468(89)80413-0

16. Gupta DK, Lall A, Bajpai M. Epigastric heteropagus twins--a report of four cases. Pediatr Surg Int. 2001 Jul;17(5-6):481-2. https://doi.org/10.1007/s003830000473 